\title{
. HYDATID HEART DISEASE WITH PAROXYSMAL TACHYCARDIA
}

\author{
BY \\ M. H. GHANEM AND A. E. DARWISH \\ From the Medical Unit, Faculty of Medicine, Farouk 1st University, Alexandria
}

Hydatid disease involving the heart is rare, although several isolated cases have been recorded: that of Neisser (1877). The heart may be affected by development of a cyst in or close to the myocardium. We wish to report a case where paroxysmal tachycardia was associated with hydatid cyst involving the myocardium.

\section{Case Report}

The patient was a butcher, aged 22 years, who had been employed at the local abattoir. He was admitted to hospital complaining of palpitation, cough, and dyspnœa of three days' duration. During this time he had suffered from several attacks of vomiting and on the day of admission had noticed that his legs had become swollen. Within the previous twelve months he had experienced three similar but less severe attacks which had lasted only a few hours. He could recall no other illnesses.

Examination disclosed an axious, well-built man who, during attacks of coughing, was expectorating blood-stained sputum. He was cyanosed and orthopnœic; his respiratory rate was sixty a minute. His temperature was $37^{\circ} \mathrm{C}$. and the pulse, which was of poor volume, was regular at 220 beats a minute. There was engorgement of the cervical veins and the enlarged liver was tender and pulsatile. The legs were odematous but there was no ascites. The lung bases were found to be congested. The cardiac impulse was in the fifth space in the mid-clavicular line. A loud systolic murmur was heard over the whole front of the heart. Except for inflamed and prolapsed internal hæmorrhoids, there were no other abnormal physical findings.

The leucocyte count was 13,600 per c.mm., with 78 per cent polymorphs; no eosinophil cells were seen. On fluroscopy, the heart was found to be symmetrically enlarged, with uniform pulsation of the cardiac borders. There was congestion of the lung fields. The electrocardiogram was that of a regular tachycardia at the rate of 214 beats a minute, and the ventricular deflections were 0.12 seconds wide. In lead CR1 small deflections producing slight notching on the ascending limb of the QRS complex could be recognized. The graph was consistent with a supraventicular tachycardia with 1:1 response. An alternative but less likely diagnosis was that of ventricular tachycardia.

Course and Treatment. A progressive deterioration in the patient's condition occurred in spite of the therapy given. In addition to general symptomatic treatment, the following measures and drugs were serially employed: (1) carotid sinus and ocular pressure both before and after $0.5 \mathrm{mg}$. prostigmine, (2) the intravenous administration of $0.25 \mathrm{~g}$. acetyl choline, (3) a full digitalising intravenous dose of cedilanide, (4) oral quinidine, $0.3 \mathrm{~g}$. 3 hourly for 48 hours, (5) potassium acetate 0.2 g. 2 hourly for 24 hours, and (6) magnesium sulphate, 4 c.c. of 50 per cent solution administered intramuscularly on two occasions.

These procedures having failed to modify the increasing congestive failure, it was decided to give $0.2 \mathrm{~g}$. quinidine hourly. A total of $1.6 \mathrm{~g}$. was administered and, in spite of the pulse slowing to 130 a minute, the patient's condition failed to improve. He died 17 days after the onset of the attack. 



Fig. 1.-Two views of the heart from behind, after incision of the swelling, showing typical hydatid cysts with multiple daughter cysts.

Post-mortem Findings. At necropsy the viscera showed the congestive changes typical of heart failure. The heart was enlarged and protruding from its posterior surface was a cystic swelling about $5 \mathrm{~cm}$. in diameter. An incision into the swelling, which had developed in the myocardium at the base of the left ventricle, showed it to be a typical hydatid cyst containing multiple daughter cysts. The cavities of the heart were free from ante-mortem thrombus. No hydatids were found in any other organ.

\section{Comment}

In hydatid disease the heart may be affected by development of a cyst in or close to the myocardium. The cardiac involvement has usually been symptomless, unsuspected, and not directly related to the cause of death (King, 1941). Alternatively, the rupture of a cyst in an organ remote from the heart may result in a sudden, fatal embolisation of daughter cysts into the blood stream. Such a mechanism has recently been reported (Khalil, 1941).

A correct ante-mortem diagnosis of hydatid cyst involving the heart has been made only once (Marten and de Crespigny, 1921). In this case the size and position of the cyst was such as to allow it to be recognized radiologically. 
The present case is considered to be of interest in that it is the first in which paroxysmal tachycardia has been associated with a hydatid cyst involving the myocardium.

\section{REFERENCES}

King, E. S. J. (1941). Surgery of the Heart. Arnold \& Co., London. Pp. 383-391.

Khalil, M. (1934). J. Egypt med. Assoc., 18, 796.

Marten, R. H., and de Crespigny, C. T. C. (1921). Med. J. Aust., 1, 287.

Neisser, A. (1877). Die Echinococcen-Krankheit. Berlin.

Rose, H. M., and Culbertson, J. T. (1940). J. Amer. med. Ass., 115, 594. 